\title{
Intradural Extramedullary Spinal Canal Space
}

National Cancer Institute

\section{Source}

National Cancer Institute. Intradural Extramedullary Spinal Canal Space. NCI Thesaurus.

Code C41450.

An area within the dura sheath but outside of the spinal cord. 